\title{
Relationship between Nomophobia and Attention among Medical Students in Jakarta, Indonesia
}

\author{
Kevin Tanoto, ${ }^{1}$ Eva Suryani, ${ }^{2}$ Satya Joewana ${ }^{2}$ \\ ${ }^{1}$ Faculty of Medicine \& Biomedical Sciences, Catholic University of Atma Jaya Indonesia, \\ Jakarta, Indonesia, ${ }^{2}$ Departement of Psychiatry Faculty of Medicine \& Biomedical Sciences, \\ Catholic University of Atma Jaya Indonesia, Jakarta, Indonesia
}

\section{Abstract}

Background: The advancements in technology in the form of smartphones have made life easier; however, some negative effects have been recorded with regards to the use of smartphone. Among these negative effects are nomophobia, or a phobia of no mobile phone, and lack of attention. This study explored the relationship between nomophobia and attention in medical students.

Methods: This was a cross-sectional analytic study on medical students in Jakarta in 2019. The nomophobia questionnaire (NMP-Q) was used to measure the level of nomophobia and the six letter cancellation test (SLCT) was used to measure attention. Data collected were analyzed using a simple linear regression test.

Results: There was a weak negative relationship between the severity of nomophobia and attention $(\mathrm{r}=0.161)$. However, nomophobia score was a very weak predictor for attention with an adjusted r-squared score of 0.021.

Conclusions: Nomophobia does not necessarily affect the attention of medical students. Excessive mobile phone use does cause nomophobia and lack of attention. Therefore, smartphones need to be used wisely.

Keywords: Attention, nomophobia, smartphone

\section{Introduction}

Inventions and improvements in technology change lifestyle. One of the inventions that have caused a big lifestyle change is the invention of handphones. Handphones that used to have simple features like sending short message services (SMS) and phone calls have now evolved into smartphones with various features. The features that smartphones provide include global positioning system (GPS), high-resolution touch screens, access to the internet, social media, even both offline and online games. ${ }^{1,2}$ The comfort and ease provided by smartphones have been a part of the lifestyle of modern society. Data provided by the Ministry of Communication and Information Republic of Indonesia (KOMINFO) has shown that there are more than 100 million active smartphone users in the year 2018. ${ }^{3}$

The ease and comfort brought by smartphones are also accompanied by several disadvantages in young adults. Students that score highly on the smartphone addiction scale (SAS) are linked with depression, anxiety, and lower sleep quality. ${ }^{4}$ Detrimental effects on physical and psychological health are also found on excessive cellular phone usage ${ }^{5}$ Smartphone usage has been used at inappropriate times and places, for example during driving, praying, studying in the library, during a lecture, and watching movies in theatres. ${ }^{6,7}$ Another disadvantage of excessive smartphone usage is nomophobia, a phobia of no mobile phone.

Nomophobia is a short form of 'NO Mobile Phone PHOBIA' that is defined as a fear of being out of mobile phone contact. This is considered as a modern age phobia introduced to our lives as a byproduct of the interaction between people and mobile information and communication technologies, especially

Correspondence: Eva Suryani, Department of Psychiatry, Faculty of Medicine \& Biomedical Sciences Catholic University of Atma Jaya Indonesia, Jalan Pluit Raya No.2, Jakarta, Indonesia, E-mail: eva.suryani@atmajaya.ac.id 
smartphones. ${ }^{8}$ A research in India has shown that college students have nomophobia with predominantly moderate nomophobes as well as severe nomophobes. ${ }^{9}$ Another study in India and Turkey have shown that college students have a high risk of having nomophobia. . $^{10,11}$ Moreover, a study in Saudi Arabia has shown that only 90 of 622 colleges student is found to be not nomophobic. ${ }^{12}$ The result shows that many smartphone users are nomophobic. This is a global problem as there has been a link between nomophobia and distraction caused by smartphones. Excessive smartphone usage is linked to a lower grade point average (GPA) and a lack of attention, resulting in a decrease in GPA. ${ }^{13}$ Nomophobia is also related to anxiety, compulsive smartphone usage, and panic. ${ }^{14}$

There are reports of excessive a mobile phone usage among medical students. The time spent on mobile phone is for recreational activities or academic improvements. Some medical students admit to being distracted by mobile phones which may affect patient safety and academic performance. Therefore, this study aimed to explore the relationship between nomophobia and attention among medical students.

\section{Methods}

This study was an analytic study using a crosssectional approach, performed among medical students of the University of Atma Jaya from November to December 2019. Based on the sample size formula for linear regression analysis, the minimum sample needed was 92 respondents. The method used to acquire respondents in this research was simple random sampling among students after class. The study was conducted after approval of the Ethical clearance that was provided by the Ethical Committee of School of Medicine and Biomedical Science, University of Atma Jaya.

Since the questionnaire was in English, the inclusion criteria were a minimum TOEFL score of 450 and had a smartphone with internet access. Students were first verbally informed about the study and those who were interested in taking part in the study filled in the informed consent form before filling in the nomophobia questionnaire (NMP-Q) to measure the level of nomophobia. Furthermore, the six letter cancellation test (SLCT) was given to measure the attention of the respondents. Finally, they were asked if they had attention disorders.

The NMP-Q was a four-dimensioned questionnaire. The dimensions were not being able to communicate, losing connectedness, not being able to access information, and giving up convenience. NMP-Q consisted of 20 items and each item was measured with a 7-score Likert scale. The scores were then summed up to get a total score from the respondents. The scores were divided into 3 categories which were mild (20-60), moderate (61-100), and severe (101-140).

The SLCT was a test where participants were given a sheet containing 33 rows and 12 columns of letters and 6 target letters (Figure). Participants were asked to identify the target letters among the 33 rows and 12 columns of letters then cancel the target letters. The time given for the participants to cancel all the letters was 1 minute and 30 seconds. The result of SLCT was the total number of letters canceled subtracted by the number of letters wrongly canceled.

Data gathered from NMP-Q and SLCT were put into Statistical Package for the Social Science (SPSS) v.22.0. A simple linear regression test was used to measure the strength of the relationship between the nomophobia score and SLCT score. A result of adjusted r-squared made into percentage was used to see if the independent variable was a good predictor of the dependent variable. The higher the percentage, the better a predictor variable explained a variable.

\section{Results}

Initially, 198 medical students were interested

Table 1 Degree of Nomophobia Severity among Medical Students in Jakarta

\begin{tabular}{lcc}
\hline \multicolumn{1}{c}{ Degree of Severity } & N & Percentage \\
\hline Mild & 39 & $20.52 \%$ \\
Moderate & 134 & $70.52 \%$ \\
Severe & 17 & $8.94 \%$ \\
\hline
\end{tabular}

Note: The NMP-Q results were categorized by score ranges of 20-60 (mild nomophobia), 61-100(moderate nomophobia), and 101-140 (severe nomophobia) 
Table 2 Average of NMP-Q and SLCT Score among Medical Students in Jakarta

\begin{tabular}{|c|c|c|c|c|c|}
\hline \multirow{2}{*}{$\begin{array}{l}\text { Undergraduate } \\
\text { Students }\end{array}$} & \multicolumn{3}{|c|}{ NMP-Q score in different categories } & \multirow{2}{*}{$\begin{array}{c}\text { NMP-Q score } \\
(p>0.05)\end{array}$} & \multirow{2}{*}{$\underset{(p>0.05)}{\text { SLCT }}$} \\
\hline & Mild & Moderate & Severe & & \\
\hline 3rd year & 47.41 & 77.69 & 111 & 73.98 & 51.40 \\
\hline 2nd year & 46.87 & 79.65 & 107.5 & 76.44 & 52.10 \\
\hline 1st year & 50.42 & 79.13 & 108.28 & 75.72 & 50.37 \\
\hline
\end{tabular}

Note: The difference in mean scores of NMP-Q and SLCT was statistically significant ( $p>0.05$ )

Table 3 NMP-Q Scores among Respondents Based on Degree of Severity

\begin{tabular}{lcccc}
\hline Degree of Severity & Mean & $\begin{array}{c}\text { Standard of } \\
\text { deviation }\end{array}$ & Minimum & Maximum \\
\hline Mild & 48.38 & 9.62 & 20 & 59 \\
Moderate & 78.60 & 9.99 & 60 & 99 \\
Severe & 109.05 & 5.61 & 100 & 122 \\
\hline
\end{tabular}

Note: The NMP-Q results were categorized as mild (20-60), moderate (61-100), and severe (101-140).

and participated in this study, however, there were 8 participants with a low TOEFL score and were thus further excluded, resulting in 190 participants consisting of 70 male $(36.8 \%)$ and 120 female $(63.2 \%)$ medical students. The degree of severity in nomophobia was shown in Table 1 , which was mild $(20.52 \%)$, moderate $(70.52 \%)$, and severe $(8.94 \%)$. The nomophobia questionnaire (NMP-Q) score and Single Letter Cancellation test (SLCT) scores among students were further compared between the year of studies as shown in Table 2.

There was in the average NMP-Q scores (F 2.187=0.301) and SLCT scores (F $2.187=0.384$ ) between the $1^{\text {st }}$ to $3^{\text {rd }}$ year, however, the difference was not statistically significant $(\mathrm{p}=0.741$ and $\mathrm{p}=0.681$, ANOVA test). Furthermore, there was no statistically significant difference in NMP-Q score $(\mathrm{p}=$ 0.666 ) between male (median=73.5) and female (median=75) students (Mann Whitney test), indicating that most of the respondents had moderate nomophobia. The average score of mild, moderate, and severe nomophobia were $48.38 \pm 9.62,78.60 \pm 9.99,109.05 \pm 5.61$, respectively. SLCT scores from each category of nomophobia were measured. The mean and standard deviation of SLCT scores from participants with mild nomophobia, moderate nomophobia, and severe nomophobia was presented in Table 4.

A Simple linear regression test was conducted, resulting in an r-value of 0.161 which indicated a weak relationship and an adjusted r-squared score of .021. This showed that the nomophobia score had a very weak relationship with the alteration in the SLCT score (Figure).

\section{Discussion}

This study explores the relationship between nomophobia and attention among young

Table 4 SLCT Scores of Respondents Based on Severity of Nomophobia

\begin{tabular}{lcccc}
\hline \multirow{2}{*}{$\begin{array}{c}\text { Severity of } \\
\text { nomophobia }\end{array}$} & Mean & $\begin{array}{c}\text { Standard of } \\
\text { Deviation }\end{array}$ & Minimum & Maximum \\
\cline { 2 - 5 } & 53.61 & 12.09 & 27 & 80 \\
Mild & 50.94 & 9.38 & 27 & 79 \\
Moderate & 48.70 & 11.22 & 28 & 66 \\
\hline
\end{tabular}

Note: The NMP-Q results were categorized as mild (20-60), moderate (61-100), and severe (101-140) 


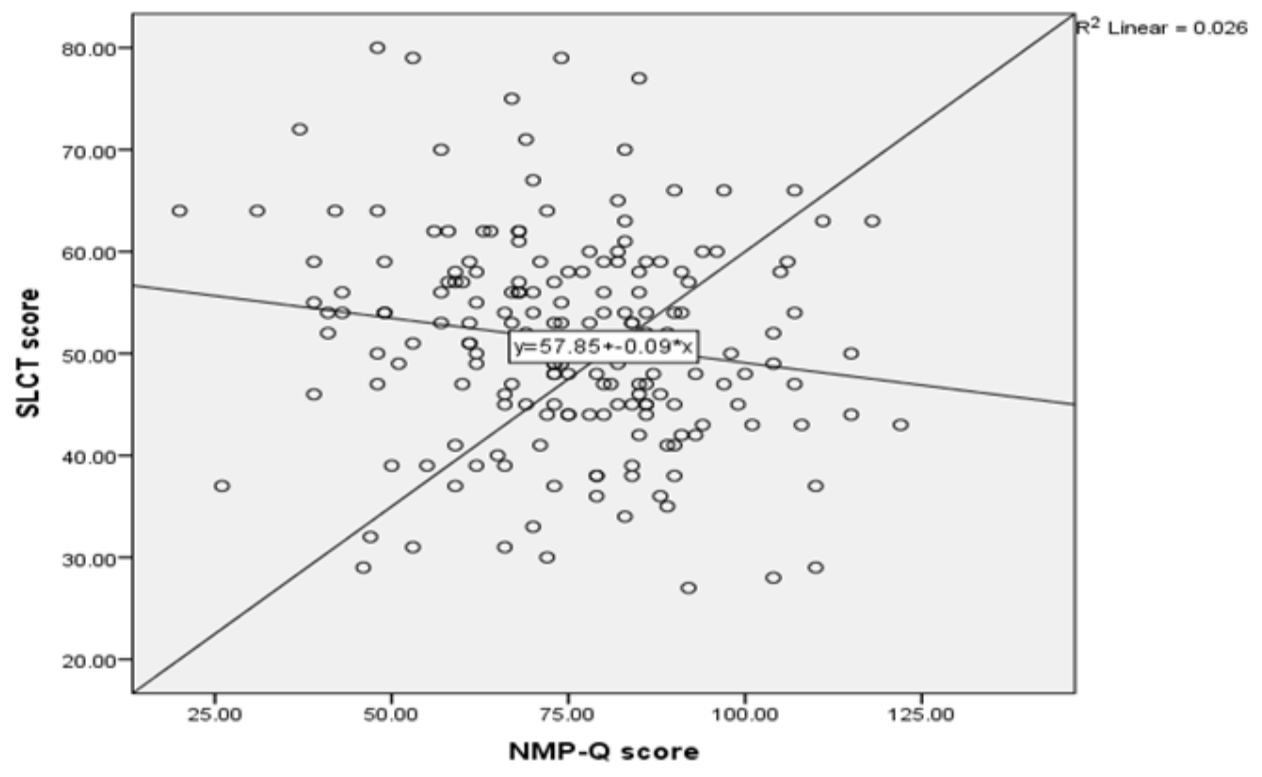

Figure Relationship between Nomophobia Score and SLCT Score

adults, especially in medical students. The study results show that nomophobia score does not explain the alteration in SLCT score and there is a negative weak correlation between them (r-value 0.161). A weak negative relationship result is also shown in a study conducted in India, that excessive mobile phone usage is linked with nomophobia and the excessive usage causes distractions which eventually lowers attention. ${ }^{10}$ Although the correlation is statistically significant $(p=<0.05)$, but the research lacks in the direct relationship between nomophobia and attention.

Distraction is also caused by the constant need to look at a mobile phones whenever 'pop up' notifications appear or when there is a need to use the feature a smartphone provides. Nomophobia can also be positively correlated with extraversion, ${ }^{15}$ and extraversion itself is related to lower levels of attention compared to introverts. ${ }^{16}$ Interestingly, various studies explore the relationship between mindfulness and nomophobia. Mindfulness, measured by the Mindful Attention Awareness Scale (MAAS), is used to measure the attention on present moment and experiences, and it seems that mindfulness has a significant and negative relationship with nomophobia. ${ }^{17}$ Another similar research performed on respondents after a 20-minute lecture. After the lecture, a quiz about the lecture was given to assess the attention of students. Participants were then asked to fill in the NMP-Q. The result shows a strong correlation between high
NMP-Q scores and lowers scores in a few parts of the quiz which indicates that there is a weak relationship between nomophobia and attention. ${ }^{18}$

The limitations of the study are that this study lacks in the screening of attention disorders such as attention deficithyperactivity disorder (ADHD), a mental health disorder that can cause above normal levels of hyperactive and impulsive behaviors, resulting in trouble focusing their attention on a single task. Furthermore, the questionnaire is in English that needs language validation to increase the same perception among respondents.

To conclude, nomophobia does not affect attention among medical students. Excessive mobile phone usage does cause nomophobia and a lack of attention, but the lack of attention is not related to nomophobia. The lack of attention found might be caused by other function of mobile phones such as pop up notifications, smartphone-related function perceived as 'productive breaks' such as games or contacting relatives, and studyrelated activities such as searching for medical guidelines. Further research needs to focus on other factors affecting attention related to excessive mobile phone usage and other adverse effects.

\section{References}

1. Min K, Lee JY, Won WY, Park JW, Min JA, Hahn C, et al. Development and validation 
of a smartphone addiction scale (SAS). PLoS One. 2013;8(2):e56936.

2. Aguilera-Manrique G, Márquez-Hernández VV, Alcaraz-Córdoba T, Granados-Gámez G, Gutiérrez-Puertas V, Gutiérrez-Puertas L. The relationship between nomophobia and the distraction associated with smartphone use among nursing students in their clinical practicum. PLoS One. 2018;13(8):e0202953.

3. Rahmayani I. Indonesia raksasa teknologi digital Asia. Jakarta: Kementerian Komunikasi dan Informatika Republik Indonesia; 2015 [cited 2018 Nov 1] Availablefrom:https://kominfo.go.id:443/ content/detail/6095/indonesia-raksasateknologi-digital-asia/0/sorotan_media.

4. Demirci K, Akgönül $M$, Akpinar A. Relationship of smartphone use severity with sleep quality, depression, and anxiety in University Students. J Behav Addict. 2015;4(2):85-92.

5. Taneja C. The psychology of excessive cellular phone use. Delhi Psychiatry Journal. 2014;17(2):448-51.

6. Billieux J, Maurage P, Lopez-Fernandez O, Kuss DJ, Griffiths MD. Can disordered mobile phone use be considered a behavioral addiction? an update on current evidence and a comprehensive model for future research. Curr Addict Rep. 2015;2:156-62.

7. Opoku RA. Attitudes towards mobile phone usage in public places among young Saudi adults. Int J Mob Commun. 2017;15(3):235-51.

8. Yildirim C, Correia AP. Exploring the dimensions of nomophobia: development and validation of a self-reported questionnare. Comput Human Behav. 2015;49:130-7.
9. Farooqui IA, Pore P, Gothankar J. Nomophobia: an emerging issue in medical institutions? J Ment Health 2018;27(5):438-41.

10. Prasad M, Patthi B, Singla A, Gupta R, Saha S, Kumar JK, et al. Nomophobia: a Crosssectional study to assess mobile phone usage among dental students. J Clin Diagn Res. 2017;11(2):ZC34-9.

11. Yildirim C, Sumuer E, Adnan M, Yildirim S. A growing fear: Prevalence of nomophobia among Turkish college students. Inform Dev. 2016; 32(5):1322-31.

12. Alahmari MS, Alfaifi AA, Alyami AH, Alshehri SM, Alqahtani MS, Alkhashrami SS, et al. Prevalence and risk factors of nomophobia among undergraduate students of health sciences colleges at King Khalid University, Abha, Saudi Arabia. Int J Med Res Prof. 2018;4(1):429-32.

13. Bragazzi NL, Del Puente G. A Proposal for including nomophobia in the new DSM-V. Psychol Res Behav Manag.2014;7:155-60.

14. Argumosa-Villar L, Boada-GrauJ,Vigil-Colet A. Exploratory investigation of theoretical predictors of nomophobia using the Mobile Phone Involvement Questionnaire (MPIQ). J Adolesc. 2017;56:127-35

15. Blumenthal TD. Extraversion, attention, and startle response reactivity. Pers Indiv Differ. 2001;31(4):495-503

16. Arpaci I, Baloğlu M, Kesici S. A multigroup analysis of the effects of individual differences in mindfulness on nomophobia. Inform Dev. 2017;35(160):1-9.

17. Mendoza J, Pody B, Lee S, Kim M, McDonough I. The effect of cellphones on attention and learning: The influences of time, distraction and nomophobia. Comput Human Behav. 2018;86:52-60. 